\title{
EDUCAÇÃO INFANTIL E FAMÍLIAS RESIDENTES EM ÁREAS RURAIS: DEMANDAS E CONCEPÇÕES EM DOIS MUNICÍPIOS DO BRASIL
}

\author{
Isabel de Oliveira e Silva \\ Iza Rodrigues da Luz'
}

\begin{abstract}
RESUMO: Este artigo tem por objetivo refletir sobre a educação infantil no Brasil e o direito das crianças e famílias residentes em áreas rurais a essa etapa da educação básica. Discutiu-se a educação da criança pequena como objeto das lutas e práticas sociais urbanas. Em seguida, foram analisadas as condições de oferta e ponto de vista de famílias moradoras de áreas rurais de dois municípios, de modo a evidenciar os dilemas e as tensóes da implementação da educação institucional de crianças de zero até seis anos residentes no campo.
\end{abstract}

Palavras-chave: Famílias rurais. Educação infantil. Educação infantil do campo.

\section{Childhood Education and families living in rural areas: demands and conceptions in two municipalities of Brazil}

\begin{abstract}
This article aims to reflect on childhood education in Brazil and the right of access to it of children and families living in rural areas. The early childhood education as an object of urban social struggles and practices is discussed. Subsequently, the conditions of supply and the point of view
\end{abstract}

\footnotetext{
${ }^{1}$ Universidade Federal de Minas Gerais, Faculdade de Educação, Programa de Pós-graduação em Educação - Belo Horizonte (MG), Brasil. E-mails: isabel.os@uol.com.br; izarodriguesluz@gmail.com

DOI: $10.1590 / C C 0101-32622017176090$
} 
of the families living in rural areas in two municipalities are presented and discussed, in order to highlight the tensions and dilemmas around the introduction of institutional education of children from zero to six years of age in rural areas.

Keywords: Rural families. Childhood education. Rural childhood education.

\section{INTRODUÇÃO}

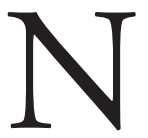

este estudo analisamos a educação infantil no Brasil e, especialmente, o direito das crianças e famílias residentes em áreas rurais a essa etapa da educação básica. As discussões aqui apresentadas partiram do pressuposto de que o preceito constitucional define que a creche e a pré-escola são direitos de todas as crianças e famílias brasileiras. Assim, sendo a educação infantil, especialmente a creche, uma instituição que nasce de lutas urbanas, e considerando o processo histórico de expansão do atendimento que excluiu as populaçóes rurais, é fundamental refletir sobre os sentidos dessa etapa da educação para as famílias e crianças residentes nesses contextos. A questão central que norteou as reflexões aqui contidas é: quais as especificidades da educação infantil para crianças residentes em áreas rurais observando as condiçóes da vida no campo e as demandas e concepçóes que suas famílias possuem? Avaliando a exiguidade da produçáo acadêmica sobre a educação de crianças de zero até seis anos residentes em áreas rurais (LIMA \& SILVA, 2015a), procurou-se, aqui, fazer uma reflexão sobre o direito dessas crianças à educação infantil bem como sobre as concepçóes, condiçóes/necessidades e demandas de suas famílias em relação ao mesmo.

\section{A EDUCAÇÃO DA CRIANÇA PEQUENA COMO OBJETO DAS LUTAS E PRÁTICAS SOCIAIS URBANAS E O DIREITO DAS FAMÍLIAS E CRIANÇAS RESIDENTES EM ÁREAS RURAIS}

Diferentes pesquisas procuraram compreender a emergência das lutas sociais pelos direitos das crianças, particularmente à educação 
e ao cuidado na faixa etária de zero a seis anos. Os diálogos com a literatura específica da educação da criança dessa faixa etária, bem como com aquela voltada para a análise dos movimentos sociais urbanos, evidenciaram que os mesmos se inseriam em um contexto mais amplo de lutas sociais por transformaçóes da sociedade brasileira, cujo cerne consistia na ideia de direito a ter direitos (TELLES, 2001; SILVA, 2008). No caso da luta por creches, dois elementos se destacam dessa literatura: trata-se de uma luta urbana; e trata-se de uma luta protagonizada por mulheres. Destaca-se ainda que os estudos que se debruçaram sobre a luta por creche foram realizados em um conjunto de análises que focalizaram os movimentos de reivindicação de serviços de consumo coletivos nas periferias das grandes cidades: a luta por moradia, por transporte público, por infraestrutura dos bairros. De acordo com Gohn (1985, p. 12), estes movimentos constituíram-se como "práticas coletivas desenvolvidas pelas classes populares".

Embora com forte acento na consideração da emergência de novos atores sociais (SADER, 1988), Gohn (1985) explicita seu entendimento de que o reconhecimento da necessidade de creche por parte do estado brasileiro, que cria uma série de açóes, baseadas na ideia de participação da população, faz parte da dominação do capitalista sobre o trabalhador. Para essa autora, trata-se, também, do atendimento de modo coletivo às exigências do capital. Nessa perspectiva, as análises destacaram as contradiçốes presentes no conjunto das lutas e das açóes voltadas para o atendimento do que passou a ser reconhecido pela sociedade como necessidade e como direito, pois havia aí, também, um projeto de fortalecimento dos mecanismos de exploração da força de trabalho das camadas empobrecidas da sociedade.

Do ponto de vista dos direitos das crianças, a literatura que emerge nos anos 1970, e ganha força nos anos 1980, aborda diferentes perspectivas em relação às necessidades e demandas por cuidado e educação das crianças de zero a seis anos. Creche e pré-escola passam a ser abordadas como partes de um grande ciclo de formação anterior à, então, escolarização obrigatória, e há um movimento claro para justificar sua pertinência ao campo da educação.

Como resultado do conjunto de lutas que envolveu movimentos sociais e uma intensa e comprometida produção aca- 
dêmica, foi se configurando o que denominamos área da educação da criança de zero a seis anos e, posteriormente, educação infantil. Temos hoje um ordenamento jurídico que assegura esse direito e o dever do Estado de ofertar creches e pré-escolas, sendo essas últimas obrigatórias a partir da Emenda Constitucional no 59, de 2009, que estabeleceu prazo de ajuste para os municípios, até 2016. Nesse ordenamento, a Lei de Diretrizes e Bases da Educação (LDB, Lei no 9.394/1996) reconheceu a educação infantil como primeira etapa da educação básica.

Para o nosso objeto de análise neste artigo, o reconhecimento do direito à creche e à pré-escola pela Constituição Federal de 1988 e, sobretudo, sua definição como parte da educação básica, obrigam aos analistas e às políticas públicas a abrangência de todas as populaçóes e ambientes de vida brasileiros. Isso supóe, necessariamente, extrapolar o ambiente urbano em que nasce a educação infantil, atingindo as diferentes populaçóes do campo. Com essa perspectiva, parece-nos fundamental nos atermos ao conceito de educação básica. Para Cury (2002, p. 294), trata-se de um conceito novo e de uma nova forma de organização da educação nacional. E que, como conceito, esclarece e administra "um conjunto de realidades novas trazidas pela busca de um espaço público novo". Para o autor, o direito à educação básica significa "um recorte universalista próprio de uma cidadania ampliada e ansiosa por encontros e reencontros com uma democracia civil, social, política e cultural". Destacamos, por essa razão, que essa noção de direito universal não pode obscurecer as condiçôes de vida no campo, devendo considerar, em sua concretização, as necessidades e demandas que daí emergem. O lugar da criança e da educação também se constitui de forma própria no contexto das lutas do campo, vinculadas à luta pela terra. Daí também surgem concepçóes de criança, de relaçóes adultocriança, criança-meio sociocultural, de trabalho etc., que configuram formas culturais de práticas educativas.

Ao longo da primeira década dos anos 2000, uma série de instrumentos legislativos e normativos incorporou os avanços dos debates e demandas sociais. A revisão das Diretrizes Curriculares Nacionais para a Educação Infantil (DCNEI) de 1999, por meio 
da Resolução no 5, do Conselho Nacional de Educação (CNE), de 2009, expressa o reconhecimento de que a determinação do direito de todas as crianças não poderia mascarar as especificidades das condiçôes de vida das crianças de diferentes meios sociais. Esse documento contempla indicaçóes para as políticas educacionais e as propostas pedagógicas para a educação de crianças de zero a seis anos em geral e, no que concerne às populaçóes rurais, aborda as especificidades das crianças filhas de agricultores familiares, extrativistas, pescadores artesanais, ribeirinhos, assentados e acampados da reforma agrária, quilombolas, caiçaras e povos da floresta.

Em um movimento de particularização desses direitos, as Diretrizes Operacionais e Complementares da Educação do Campo, aprovadas pelo CNE, respectivamente, nos anos de 2002 e 2008, incorporaram orientaçôes para a educação das crianças na faixa etária de zero até seis anos.

Embora tenhamos tido, nos últimos anos, ações importantes no sentido da construção de referências para a política de educação infantil voltada para as crianças que vivem fora dos centros urbanos, trata-se ainda de uma discussão incipiente. O Ministério da Educação, por meio da Coordenação de Educação Infantil (COEDI), em diálogo com movimentos sociais e universidades, estimulou e empreendeu açóes, especialmente a partir de 2010, com o objetivo de conhecer a realidade da vida no campo incluindo as condiçóes de oferta de educação infantil. Desses atos, o de maior fôlego foi a realização da Pesquisa Nacional Caracterização das práticas educativas com crianças de 0 a 6 anos de idade residentes em área rural, desenvolvida em duas etapas. $\mathrm{Na}$ primeira, foi feita uma pesquisa quantitativa com aplicação de questionários em uma amostra de 1.130 municípios das cinco regióes do país. Na segunda, foram realizados estudos qualitativos em 30 municípios dessa primeira amostra, sendo 6 municípios por região.

Neste artigo, focalizamos elementos dos estudos qualitativos realizados em dois municípios da região sudeste no contexto da referida pesquisa: um no estado de Minas Gerais e outro no estado de São Paulo. 


\section{CONDIÇÕES DE OFERTA E PONTO DE VISTA DE FAMÍLIAS SOBRE EDUCAÇÃO INFANTIL EM ÁREAS RURAIS}

Neste item, abordamos elementos das necessidades, demandas e concepções de famílias residentes nesses municípios. Esses atores são tomados como sujeitos de direitos em diferentes âmbitos, o que inclui o direito a contar com educação infantil para seus filhos e filhas. A ideia de necessidades e demandas está sendo aqui entendida, conforme Pereira (2006), ou seja, por meio da relação entre políticas públicas e necessidades humanas. Para essa autora, o conceito de necessidade não se opóe ao de direito. Ao contrário, ela problematiza as perspectivas neoliberais para as quais, levadas ao extremo, sequer se poderia falar em necessidades sociais, pois não passariam de mistificaçóes que levariam à imposição do Estado sobre as liberdades individuais. São perspectivas teóricas individualistas que só admitem a presença do Estado em situaçóes de extrema pobreza, portanto, sem relação com o estatuto de cidadania. Trata-se, pois, de ouvir o que dizem pessoas e grupos singulares, considerando-se que expressam necessidades humanas compartilhadas, portanto sociais e relativas aos seus direitos como cidadáos. Reconhece-se, portanto, a existência de sujeitos, em determinadas condiçóes de vida e portadores de cultura por meio e no interior das quais constroem suas necessidades e formulam suas demandas.

No caso das populações residentes em áreas rurais no Brasil, historicamente excluídas de direitos, a oferta de educação em geral foi marcada por ausência de consideração das condiçóes de vida e culturais que lhes caracterizam. Tratando-se da educação infantil, mesmo para as áreas urbanas, encontramo-nos ainda em processos de construção de referências sobre em que consiste cuidar e educar bebês e crianças pequenas em instituiçóes de educação infantil, tendo como princípio a ideia de compartilhamento entre famílias e instituição educativa. Esse último aspecto, o do compartilhamento do cuidado e educação dos filhos e filhas entre as famílias e a instituição educacional, como indicado pela legislação brasileira, é a chave segundo a qual buscamos compreender as necessidades, demandas e concepçóes de familiares de crianças em idade de frequência à educação infantil. 
Lima e Silva (2015a) alertam para a raridade das pesquisas cuja temática seja a família de crianças pequenas residentes no campo e a relação entre creches/pré-escolas e famílias. Constatam que, nesses contextos, é comum que as escolas que atendem outros níveis de educação básica tenham turmas da educação infantil. Os poucos estudos encontrados investigaram a relação entre a escola e as famílias, sem tratar especificamente dessa primeira etapa da educação. Indicaram a presença e a participação efetiva das famílias na escola, além da valorização de suas práticas na dinâmica e gestáo escolares. $\mathrm{Na}$ pesquisa feita por Lima e Silva (2015a), ao investigarem a relação escola-família em uma escola de educação infantil localizada em área rural, foi encontrada uma situação semelhante à descrita em estudos relativos ao contexto urbano, em que predominam desencontros, conflitos e tensōes. As significaçóes dessa relação estavam atravessadas e configuradas pelas especificidades do contexto pesquisado:

- $\quad$ dispersão e distância geográfica entre escola e famílias;

- $\quad$ restrições no transporte escolar;

- $\quad$ significaçóes e formato das atividades de encontro com as famílias realizadas pela escola; e

- dificuldades de locomoção e isolamento das famílias.

Estes resultados possibilitaram às autoras reforçarem os argumentos sobre a importância de considerar a heterogeneidade do campo brasileiro e a necessidade de reconhecer e entender as diversas ruralidades e urbanidades que caracterizam o nosso país, como algo essencial para a construção de uma educação infantil democrática.

Com o objetivo de dar visibilidade a essa heterogeneidade é que foram escolhidos os dois municípios onde residiam as famílias que concederam as entrevistas que subsidiaram as reflexóes aqui realizadas, pois apresentavam condiçóes de oferta que exemplificam parte da diversidade presente nos municípios brasileiros. As informaçóes sobre os municípios e as famílias foram retiradas do volume 3 do relatório 3 da pesquisa nacional acima referida, que apresentou os dados da pesquisa 
qualitativa realizada na regiáo sudeste. Mantivemos inclusive a mesma identificação dos municípios utilizada no relatório: município B e município F (BRASIL, 2012).

Faremos as reflexóes sobre as concepções e demandas das famílias contextualizando brevemente as informaçóes sobre a oferta da educação infantil nos municípios onde residiam.

\section{MUNICÍPIO B}

De acordo com o Censo de 2010, o município B, localizado no estado de São Paulo, possuía 208.662 habitantes, sendo que 15\% tinham entre 0 e 5 anos e desses $8,2 \%$ residiam em área rural, sendo majoritariamente urbano com somente $2,8 \%$ dos domicílios em zona rural. As populaçóes dessas áreas eram compostas por trabalhadores rurais assalariados, agricultores familiares e por assentados. Os dados econômicos indicaram que as atividades desenvolvidas nessa área representavam somente $1,5 \%$ do produto interno bruto (PIB) e que o município apresentava uma renda per capita acima da encontrada para a região sudeste e uma distribuiçáo de renda melhor do que a média nacional. (IBGE, 2010; BRASIL, 2012).

Sobre a oferta de educação infantil para as crianças de zero até seis anos de idade residentes em áreas rurais no município, em 2012, ano da pesquisa, constatou-se que elas eram atendidas em escolas localizadas onde moravam. Nesse ano, estavam matriculadas 68 crianças na creche e 71 na pré-escola. Conforme informaçóes da Secretária Municipal de Educação e das diretoras das duas escolas visitadas, não havia lista de espera, sendo a oferta maior do que a demanda. No município, os bebês e crianças de até três anos eram transportados para as escolas com a companhia de suas mães. As gestoras entrevistadas destacaram essa forma de transporte como aspecto a ser melhorado, pois implicava um tempo e disponibilidade da mãe, que podiam trazer prejuízos em suas outras tarefas (BRASIL, 2012).

Nesse município, foram entrevistadas seis famílias que residiam em dois assentamentos. Duas delas tinham filhos matriculados nas 
escolas de educação infantil e quatro tinham filhos não matriculados. As duas famílias usuárias se identificaram como agricultores familiares; a primeira tinha um menino de um ano e quatro meses, e a segunda um menino de três anos matriculados na creche. Entre as quatro famílias não usuárias, duas se identificaram como agricultores familiares e duas como agricultores. A primeira tinha uma menina de nove meses; a segunda uma menina de dez meses; a terceira um menino de sete meses e um menino de dois anos; e a quarta uma menina de dois anos de idade (BRASIL, 2012).

As entrevistas tiveram como objetivo conhecer o que famílias usuárias e não usuárias da educação infantil pensavam sobre esse atendimento. No caso das segundas, o propósito era compreender as razóes da não matrícula das crianças, de modo a entender os aspectos relacionados às condiçóes da oferta bem como aos valores que orientavam os responsáveis na criação dos filhos.

Diante da pergunta relativa à qualidade da educação infantil ofertada pelo município, as famílias o classificaram como muito bom. Explicitaram que ficavam tranquilas quando deixavam seus filhos nas escolas. Em relaçáo ao transporte, alguns destacaram o inconveniente da ausência de profissional para acompanhar os bebês e crianças de até três anos, aspecto esse indicado como desafio pelas gestoras. Além disso, as condiçóes das estradas foram mencionadas como aspecto que gerava insegurança (BRASIL, 2012).

No que se refere ao sentido que a educação infantil possuía para as famílias, as mães usuárias explicitaram a importância dessa instituição para seus filhos, indicando o reconhecimento dessa educação como um direito das crianças. Entre as famílias não usuárias, apareceram concepções mais ligadas à educação infantil como algo voltado para as mães que trabalham, ou seja, como um direito das famílias. Uma das mães afirmou que se precisasse colocaria seu filho na escola, mas como não precisava preferia tê-lo em casa. Informou ainda que considerava a idade de três anos como a mais apropriada para as crianças irem para a escola (BRASIL, 2012).

As famílias confirmaram que existiam mais vagas do que a demanda de matrículas. Indicaram também que o atendimento em pe- 
ríodo integral era de escolha prioritária das mães que trabalhavam e que algumas delas preferiam o período parcial, para terem a companhia da criança em casa em parte do dia (BRASIL, 2012).

As entrevistas com as famílias do município B nos possibilitam assinalar, assim como destacado por Lima e Silva (2015a), a importância de reconhecer as particularidades do contexto em que ocorre a oferta de educação infantil para as crianças residentes em áreas rurais. Nesse município, fica explícita a relevância do transporte como elemento desafiador na oferta e demanda dessa etapa da educação básica. Assinalamos, inclusive, que a oferta estava sendo feita conforme os normativos legais, ou seja, em escolas localizadas na zona rural; mas mesmo nessa situação, o município não conseguia assegurar que ficassem próximas da residência de todos os bebês e crianças.

Outro elemento de tensão se refere à compreensão do direito à educação infantil como algo também das crianças e não somente de suas famílias. Como assinalado por Rosemberg (1999), vemos que entre essas famílias existe também a concepção de que a escola é voltada para atender as mães que trabalham e que se essa condição não está presente, os bebês e crianças devem permanecer em casa. Vê-se aqui também reproduzido o ideário do cuidado materno como o que há de melhor para os filhos e de que só deve ser substituído nas situaçóes em que essa mãe não possa oferecê-lo.

\section{MUNICÍPIO F}

O município F, localizado no estado de Minas Gerais, é o maior município em extensão territorial, e o terceiro em população urbana e geral do norte desse estado. Em 2010, dos 65.464 habitantes, 41.328 (63\%) residiam em área urbana e 24.136 (37\%) na zona rural. Nessa última estavam 2.938 crianças de 0 até 6 anos de idade. Em relação às populações do campo, os agricultores familiares, quilombolas e ribeirinhos foram identificados entre as famílias das crianças de três a seis anos de idade residentes em área rural e matriculadas na rede municipal (IBGE, 2010; BRASIL, 2012). 
Em 2012, ano de realização da pesquisa, não havia oferta de educação infantil para os bebês e crianças de até dois anos residentes no campo do município F. Para as crianças de três a seis anos, a oferta acontecia na zona rural, em escolas de educação infantil e também em prédios ou salas anexas a escolas públicas de ensino fundamental e salas multisseriadas de ensino fundamental. Destacamos que esse último tipo de oferta contrariava as determinaçóes da Resolução no 2 , de 2008, que trata da educação do campo, por agrupar as crianças da educação infantil com crianças do ensino fundamental (BRASIL, 2012).

Em 2012, existiam 479 crianças residentes em áreas rurais frequentando a educação infantil, sendo: 55 crianças de 3 anos, 190 de 4 anos e 234 de 5 anos. Considerando esses números e o total de crianças de 0 a 6 anos de idade residentes em área rural, o município atendia somente cerca de 16,3\% dessa população (BRASIL, 2012).

$\mathrm{Na}$ entrevista com a Secretária Municipal de Educação do município F, ficou evidenciado que a baixa cobertura de atendimento da educação infantil para as crianças residentes em área rural estava relacionada com dificuldades do município também com o atendimento do ensino fundamental. A gestora informou que as características geográficas do município, que conta com 242 comunidades na zona rural dispersas por seu território, sendo boa parte delas distantes da sede, dificultam a oferta e trazem muitos desafios também para o transporte das crianças. A diretora de educação do campo e sua vice confirmaram esses dados e reforçaram os desafios da gestão das escolas da zona rural, visto que há comunidades cujo acesso é bastante difícil e que por essa razão não era possível fazer um acompanhamento mais próximo (BRASIL, 2012).

No município F, foram entrevistadas cinco famílias. Dessas, três tinham filhos matriculados na educação infantil e duas, filhos não matriculados. Entre as três famílias usuárias, duas se identificaram como agricultoras e na outra as ocupaçóes dos pais não eram relacionadas ao campo. As três famílias tinham meninas de cinco anos matriculadas na pré-escola. A primeira família não usuária se nominou como de agricultores e tinha um menino de quatro anos. A segunda tinha um menino de dois anos e quatro meses e a ocupação do pai não estava relacionada ao campo (BRASIL, 2012). 
As três famílias com crianças matriculadas na educação infantil afirmaram que não tiveram dificuldades para conseguir vaga para os filhos de quatro e cinco anos e confirmaram a inexistência do atendimento para bebês e crianças de zero a dois anos. As famílias com crianças não matriculadas informaram que não existia a oferta de educação infantil na comunidade onde moravam e que só havia vaga para os pequenos a partir dos seis anos. Afirmaram ainda o desejo de que seus filhos frequentassem a escola desde a creche. Conforme essas famílias, a distância das instituiçóes e a inexistência do transporte escolar era o grande empecilho para o acesso de seus filhos à educação infantil. Afiançaram ainda que as crianças maiores da comunidade já precisaram andar sete quilômetros para chegar à escola, antes da prefeitura oferecer o transporte escolar (BRASIL, 2012).

No município F, também se destacam as particularidades do contexto, nesse caso: grande extensão territorial, dispersão das populaçóes residentes na zona rural e dificuldades na oferta do ensino fundamental. Com essas características, não havia creche e atendia somente uma pequena parcela das crianças de três a seis anos residentes em áreas rurais. As entrevistas com as famílias indicaram a valorização da educação infantil e a concepção da mesma como um direito das crianças. As famílias não usuárias declararam o desejo de que seus filhos tivessem esse direito assegurado. Vê-se aqui, entretanto, o quanto o direito à educação básica presente nos normativos ainda é algo distante para a maioria das crianças de zero a seis anos que ali residem e o quanto as condiçóes de acesso à educação infantil se diferenciam do que foi apresentado no município B. Essa comparação reforça a necessidade do reconhecimento da heterogeneidade do campo brasileiro, conforme assinalam Lima e Silva (2015a). Além disso, a realidade do município F permite também a constatação do que já foi apontado por Lima e Silva (2015b), Rosemberg e Artes (2012) e Souza (2012), de que a violação do direito das comunidades à educação se configura de forma mais drástica nas áreas rurais.

No município F, o transporte escolar também apareceu como um elemento importante no acesso à educação infantil para as crianças residentes em áreas rurais. Esse foi o único município, dentre os pesquisados na região sudeste, em que encontramos crianças que não têm 
acesso à pré-escola, tanto por ausência de escolas próximas às suas residências, quanto pela falta do transporte escolar. Os dois municípios se diferenciam do ponto de vista socioeconômico, mas ambos apresentaram questóes a respeito do transporte escolar. Identificou-se, por meio dos depoimentos das famílias e de gestoras dos municípios B e F, a necessidade de mais estudos e reflexóes sobre o mesmo, pois como enfatizado por Silva et al. (2012), é uma das especificidades da educação infantil do campo e afeta diretamente a sua qualidade. Lembramos ainda que o direito ao transporte escolar gratuito também está presente na Constituiçáo Federal, de 1988, no Estatuto da Criança e do Adolescente de 1990 e na LDB de 1996.

Considerando os dois municípios, em que pesem as diferenças geográficas, culturais, econômicas e relativas ao grau de organização das populaçóes residentes em áreas rurais, ouvir as famílias (e também as gestoras) permitiu constatar que a educação infantil como direito ainda demanda especificação e formas de operacionalização que considerem as necessidades, na acepção acima desenvolvida (PEREIRA, 2006). De um lado, é preciso considerar aspectos relacionados à constituição histórica do lugar da mulher e da criança que ainda perpassam o imaginário tanto de famílias residentes em áreas urbanas quanto em áreas rurais. Essas últimas, no entanto, tendo em vista a menor tradição de oferta, possivelmente se veem ainda mais fortemente vinculadas a esse ideário, o que pode contribuir para que a demanda não se manifeste, ou até mesmo, como no caso do município B, que haja vagas ociosas. Se levarmos a efeito a ideia de necessidades compartilhadas discutidas anteriormente (PEREIRA, 2006), e se considerarmos que, no Brasil, todo um movimento de reconhecimento de que as crianças podem se beneficiar da convivência com pares em instituiçóes de educação infantil e que, fundamentalmente, esta é a raiz da educação básica (CURY, 2002), compete ao poder público fazer chegar a essas populaçóes o serviço e as referências sobre ele. Essa dimensão está afeta ao caráter de universalidade do direito.

Já no que concerne às necessidades dos grupos específicos, a análise das condiçóes de oferta desses dois municípios e a escuta de famílias usuárias e não usuárias da educação infantil nos indicam elementos importantes e desafiadores para as políticas de educação. 
De um lado, é preciso considerar como a educação infantil está normatizada para o conjunto das crianças brasileiras de zero até seis anos e a importância de que a oferta para as residentes em áreas rurais não empobreça a experiência em nome de adequaçóes ao contexto. De outro, a realidade apresenta características que o modelo urbano - que serviu de base para a normatização geral — não atende. Assim, a normatização específica para a educação infantil do campo, já existente, precisa fazer parte do conjunto de orientaçóes das políticas educacionais para a área em níveis nacional e municipal.

Chamou a atenção, especialmente, algo já identificado pela literatura sobre educação do campo: a centralidade que a dispersão da população residente em área rural adquire para a realização da oferta. As racionalidades econômica (que rege as definiçốes sobre onde serão construídas escolas) e pedagógica dominantes (em que os projetos supóem segregação de idades internamente ao intervalo que vai de zero até seis anos), não se apresentam como boas orientaçóes da política de educação infantil para as áreas rurais. Além disso, a política educacional não conseguirá, isoladamente, superar os obstáculos impostos pelas características socioeconômicas ou geográficas das áreas rurais. Sem uma política de mobilidade intracampo, com estradas adequadas e conservadas; sem a concepçáo de meios de transporte adequados à idade das crianças e ao clima das diferentes regióes, dificilmente teremos, para os casos em que o transporte se revele apropriado, situação de conforto e segurança para crianças e adultos.

\section{CONSIDERAÇÕES FINAIS}

Entre as conclusóes do estudo evidencia-se o quanto ainda desconhecemos as crianças e famílias moradoras das áreas rurais de nosso país e o quanto o acesso ao direito à educação infantil já normatizado e reconhecido ainda é algo distante para boa parte desses sujeitos, como já assinalado por Rosemberg e Artes (2012). Possibilitou também que percebêssemos que a oferta e a demanda por educação infantil apresentam dilemas e tensóes semelhantes ao que já se verificou como características presentes nos contextos urbanos, como a inexistência de vagas para todas 
as crianças e a exigência do trabalho materno como critério de seleção para o atendimento de bebês e crianças. A questáo do transporte, que tanto se destacou nos dois municípios investigados, também se coloca nos contextos urbanos, quando consideramos as grandes cidades e o local de moradia de parte dos bebês e crianças atendidos e, também, o lugar de trabalho dos pais. Esses elementos assinalam a urgência de novos investimentos e estudos que possibilitem a efetivação do direito à educação infantil para todas as crianças brasileiras e especialmente para aquelas residentes em áreas rurais, considerando que a oferta deve contemplar a especificidade de seus contextos.

\section{REFERÊNCIAS}

BRASIL. Ministério da Educação, Universidade Federal do Rio Grande do Sul. Pesquisa Nacional Caracterização das Práticas Educativas com Crianças de 0 a 6 anos de Idade Residentes em Áreas Rurais. Relatório 3 - Região Sudeste. Brasília/ Porto Alegre: MEC/UFRGS, 2012. v. 3. Disponível em: $\leq$ http://portal.mec. gov.br/index.php?option=com_content $\& v i e w=$ article $\&$ id $=12579$ :educacaoinfantil\&Itemid=1152>. Acesso em: 19 out. 2016.

CURY, C.R.J. A educação básica no Brasil. Educação e Sociedade, Campinas, v. 23, n. 80, p. 168-200, set. 2002.

GOHN, M. G. M. A força da periferia: a luta das mulheres por creches em São Paulo. Petrópolis: Vozes, 1985.

INSTITUTO BRASILEIRO DE GEOGRAFIA E ESTATÍSTICA (IBGE). Censo demográfico 2010. 2010. Disponível em: shttp://www.ibge.gov.br/home/ estatistica/populacao/censo2010/default.shtm>. Acesso em: 15 maio 2012.

LIMA, L.P.; SILVA, A.P.S. A relação entre a educação infantil e as famílias do campo. Psicologia Escolar e Educacional, v. 19, p. 475-483, 2015 a.

- Educação infantil no campo: o atendimento em um município de Minas Gerais-Brasil. Nuances, v. 26, p. 130-146, 2015 b.

PEREIRA, P.A.P. Políticas públicas e necessidades humanas com enfoque de gênero. Sociedade em Debate, Pelotas, v. 12, n. 1, p. 67-86, jun. 2006.

ROSEMBERG, F. A expansão da educação infantil e processos de exclusão. Cadernos de Pesquisa, São Paulo, n. 107, p. 7-40, jul. 1999. 
ROSEMBERG, F.; ARTES, A. O rural e o urbano na oferta de educação para crianças de até 6 anos. In: BARBOSA, M.C.S. (Org.). Oferta e demanda de educação infantil no campo. Porto Alegre: Evangraf, 2012. p. 13-69.

SADER, E. Quando novos personagens entraram em cena: experiências e lutas dos trabalhadores da Grande São Paulo, 1970-1980. Rio de Janeiro: Paz e Terra, 1988.

SILVA, A.P.S.; PASUCH, J.; SILVA, J.B. Educação infantil do campo. São Paulo: Cortez, 2012.

SILVA, I.O. Educação infantil no coração da cidade. São Paulo: Cortez, 2008.

SOUZA, M.A. Educação do campo, desigualdades sociais e educacionais. Educação e Sociedade, Campinas, v. 33, n. 120, p. 745-763, 2012.

TELLES, V.S. Pobreza e cidadania. São Paulo: 34, 2001.

Recebido em 20 de fevereiro de 2017.

Aprovado em 20 de junho de 2017. 